\title{
Temporal Artery Compression Sign - A Novel Ultrasound Finding for the Diagnosis of Giant Cell Arteritis
}

\section{Das Kompressions-Zeichen - ein neues, ultraschall-basiertes Merkmal zur Diagnose der Riesenzellarteritis}

\author{
Authors \\ M. Aschwanden ${ }^{1 *}$, T. Daikeler ${ }^{2 *}$, F. Kesten ${ }^{3}$, T. Baldi ${ }^{1}$, D. Benz ${ }^{2}$, A. Tyndall ${ }^{2}$, S. Imfeld ${ }^{1}$, D. Staub ${ }^{1}$, C. Hess ${ }^{3 *}$, \\ K. A. Jaeger ${ }^{*}$ \\ Affiliations \\ 1 Departement of Angiology, University Hospital Basel
2 Departement of Rheumatology, University Hospital Basel
3 Medical Outpatient Departement, University Hospital Basel
}

Key words

- vascular

ultrasound color Doppler

- vasculitis

- temporal artery

received $\quad 21.2 .2012$

accepted 23.3.2012

Bibliography

Dol http://dx.doi.org/

10.1055/s-0032-1312821

Published online: June 12, 2012

Ultraschall in Med 2013; 34:

47-50 @ Georg Thieme Verlag

KG Stuttgart · New York .

ISSN 0172-4614

\section{Correspondence}

\section{Dr. Markus Aschwanden}

Angiology, University Hospital Petersgraben 4

4031 Basel

Switzerland

Tel.: ++41/61/2655153

Fax: $++41 / 61 / 2655356$

aschwandenm@uhbs.ch

\section{Zusammenfassung \\ $\nabla$}

Ziel: Das perivaskuläre Halo-Zeichen der Temporalarterie gilt als zuverlässiges diagnostisches Zeichen zum Nachweis einer Riesenzellarteritis (RZA), ist aber auch für erfahrene Spezialisten anspruchsvoll zu dokumentieren. In dieser Studie wurde erstmals untersucht, ob die einfacher durchzuführende Methode der Kompression der Temporalarterie (Kompressions-Zeichen) ein ausreichend gutes Zeichen darstellt, um die veränderte Gefäßwand bei Patienten mit RZA zuverlässig zu erkennen.

Material und Methoden: Patienten mit Verdacht auf RZA wurden zwischen März 2009 und September 2011 prospektiv eingeschlossen. Bei allen Patienten wurde bilateral mittels Ultraschall ein Halo- resp. ein Kompressionszeichen der Temporalarterie gesucht. Eine persistierend sichtbare Temporalarterie unter vollständiger Kompression des Gefäßes wurde als positives Kompressions-Zeichen gewertet. Die endgültige Diagnose RZA versus „andere Diagnose“ wurde durch Fachärzte, welche nicht in die Ultraschalluntersuchung involviert waren, unter Berücksichtigung aller Befunde und der ACR-Kriterien gestellt.

Ergebnisse: 43/80 Patienten wiesen eine RZA auf, 34 davon mit positivem Halo- resp. KompressionZeichen. Keiner der 37 Patienten ohne RZA hatte ein positives Halo- oder Kompressionszeichen. Die Sensitivität resp. Spezifität des Halo- und des Kompressions-Zeichens bezogen auf die Diagnose RZA betrug für beide je $79 \%$ resp. $100 \%$.

Schlussfolgerung: In diesem Kollektiv von Patienten mit vermuteter RZA wiesen das Halo- und das Kompressions-Zeichen die gleiche diagnostische Wertigkeit auf. Die einfachere Anwendbarkeit und die diagnostische Zuverlässigkeit des Kompressions-Zeichens haben das Potenzial, zukünftig die Diagnostik in diesem Bereich zu erleichtern. Das Kompressions-Zeichen sollte deswegen weiter prospektiv evaluiert werden.

\section{Abstract \\ $\nabla$}

Purpose: In patients with suspected giant cell arteritis (GCA), a search for the perivascular halo sign, a sophisticated color duplex ultrasound (CDU) finding, at experienced centers reliably identifies inflamed temporal arteries (TA). We tested whether TA compression in patients with GCA, a simple, largely operator-independent maneuver, elicits contrasting echogenicity between the diseased artery wall and the surrounding tissue (compression sign). Materials and Methods: 80 individuals with suspected GCA were prospectively enrolled in this single-center study. In all study participants, bilateral ultrasound examination of the TA established the presence/absence of the halo and compression sign. A positive compression sign was defined as visibility of the TA upon transducer-imposed compression of the artery. Based on ACR criteria, a team of specialized physicians independently grouped patients as GCA versus non-GCA.

Results: 43/80 study participants were grouped as GCA. Both the halo sign and the compression sign were positive in 34/43 patients in the GCA group, and negative in all 37/37 of the non-GCA group, resulting in a sensitivity of $79 \%$ and a specificity of $100 \%$ for both the halo and the compression sign.

Conclusion: In this cohort of individuals with suspected GCA, the halo sign and the compression sign were equal in their diagnostic performance. The simplicity of the compression sign suggests a level of reliability warranting further evaluation. 


\section{Introduction}

$\nabla$

Giant cell arteritis (GCA) is the most common idiopathic vasculitis syndrome, affecting medium and large-sized arteries. Although the involvement of large arteries throughout the body is increasingly recognized, the only direct evidence for the diagnosis remains the histological finding of characteristic vascular inflammation in biopsy samples [1,2]. Due to the segmental nature of the inflammatory process in GCA ("skip lesions"), biopsies - most commonly performed on temporal arteries (TA) - can provide false-negative results, hampering the sensitivity of this diagnostic procedure [3].

In 1997, Schmidt et al. introduced color duplex ultrasound (CDU) as a noninvasive method for differentiating inflamed from noninflamed TA segments [4]. In this seminal publication, the halo sign was demonstrated to provide excellent accuracy for the diagnosis of GCA. Subsequent studies reported less convincing results, pointing at relevant operator dependency (experience, equipment) of the diagnostic approach as established by Schmidt et al. $[5,6]$. In search of a simple, robust and less operator-dependent ultrasound-based diagnostic tool, we used a prospective cohort of individuals with suspected GCA to compare the diagnostic accuracy of the halo sign and a novel vascular ultrasound phenotype - namely visibility vs. loss of visibility of the TA upon transducer-imposed artery compression.

\section{Patients and Methods}

$\nabla$

Consecutive patients with a clinical suspicion of GCA were included in the study between 3/2009 and 9/2011 at the University Hospital Basel, Switzerland. The study was conducted as a nested project of the IRB-approved prospective Basel Riesenzell-Arteritis Kohorte ('BARK') study. TA biopsy was performed if deemed indi- cated by the referring physician. The biopsy side was guided by CDU in the case of a positive finding. Definite diagnosis after extensive clinical, laboratory and imaging evaluation was established by a team of independent and experienced rheumatologists/immunologists not involved in CDU according to ACR criteria [1, 7], and patients were accordingly grouped as GCA vs. non-GCA.

Bilateral CDU evaluation of the TA was performed in all study participants, using an iU22 duplex ultrasound (Philips, Best, Netherlands) with a linear 5-17 MHz broadband transducer. The B-scan and Doppler settings were adjusted for best assessment of the arteries. The TA (trunk, frontal and parietal branch) was scanned in the cross section; the longitudinal section was used to detect stenoses. Blinded to the patients' diagnosis, a team of 3 senior physicians - each with more than 6 years of CDU experience - performed the ultrasound examinations. One physician performed the entire examination in any given patient. The order of examination (halo sign vs. compression sign) was left to the discretion of the examiner.

Compression sonography was conducted as follows: slight pressure was applied via the transducer to occlude the TA. Pressure was applied until the lumen was occluded and no arterial pulsation remained visible by B-mode. The contact area of the transducer with the scalp was positioned so that osseus structures did not impede the compression of the artery. The compression sign was considered negative (absence of evidence for vasculitis) if the arterial wall did not contrast with the surrounding tissue upon compression. If, however, the arterial wall remained visible upon compression, i. e., echogenicity different than the surrounding tissue due to vessel wall inflammation, the compression sign was considered positive (evidence of vasculitis) ( $\bullet$ Fig. 1 ). The halo sign, stenoses or occlusion was searched for as described elsewhere in detail [4]. Statistical analysis was performed using SPSS/PC (version 19.0, SPSS Inc, Chicago). Comparisons between patients categorized as
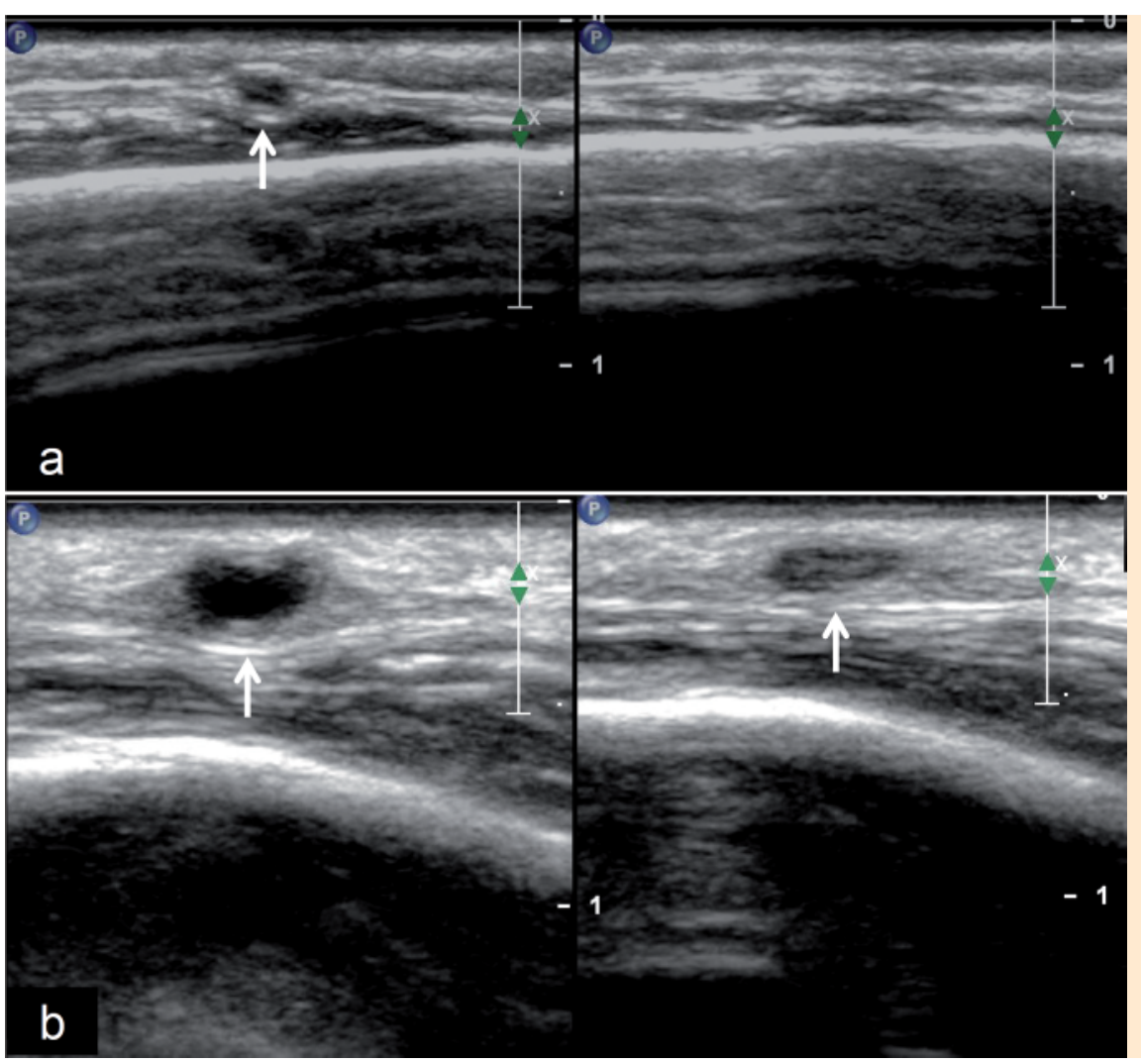

Fig. 1 The compression sign. a Loss of visibility of the temporal artery (lumen and wall) upon transducer-imposed compression (= compression sign negative/lack of evidence of vasculitis). b Visibility of the temporal artery wall maintained upon transducer-imposed compression (= compression sign positive/evidence of vasculitis). Arrows indicate temporal arteries.

Abb. 1 Das „Kompressions-Zeichen“. a Temporalarterie (Lumen und Wand) ist unter vollständiger Kompression nicht mehr nachweisbar (= negatives „Kompressions-Zeichen“/kein Hinweis auf Vaskulitis). b Weiterhin sichtbare Gefäßwand unter vollständiger Kompression der Temporalarterie (= positives „Kompressions-Zeichen“/Nachweis einer Vaskulitis). Pfeil weist auf Temporalarterie. 
GCA vs. non-GCA were made using unpaired Student's t-tests for independent samples or Mann-Whitney-U-tests and Chi-square tests, as appropriate. All hypothesis testing was two-tailed.

\section{Results \\ $\nabla$}

\section{Patient Characteristics}

The mean age of the 80 study participants was 72 years $( \pm 10$ years SD), and $69 \%$ of the patients were female. All study participants were referred for vascular ultrasound based on the clinical suspicion of GCA. In 43/80 study participants (54\%), the final diagnosis was GCA. The remaining 37 patients (46\%) in the non-GCA group were diagnosed with polymyalgia rheumatica $(n=14)$, rheumatoid arthritis ( $\mathrm{n}=3)$, carcinoma $(\mathrm{n}=4)$, amaurosis fugax $(\mathrm{n}=2)$, anterior ischemic optic neuropathy $(n=2)$, small vessel vasculitis $(n=3)$, and retinal detachment, pneumonitis, enthesitis, neuralgia of the trigeminal nerve, ulcerative proctitis, diabetes mellitus, syncope, coronary artery disease, and familial Mediterranean fever $(n=1$ in each case).

In 53/80 study participants (66\%), a TA biopsy was performed. In the 43 patients with GCA, 38 underwent a TA biopsy, among them 20 showed active vasculitis. One biopsy revealed only a venous segment and was therefore not conclusive. In the 37 patients categorized as non-GCA, 15 underwent a TA biopsy. None of them showed active vasculitis. At the time of CDU examination, steroid therapy was initiated in $47 / 80$ study participants (59\%), and at the time of biopsy in 45/53 individuals (85\%). Patient characteristics, including the median number of days participants were treated with steroids and the median number of days CDU was performed before TA biopsy in each subgroup, are summarized in $\bullet$ Table 1.

\section{Diagnostic Performance of Vascular Ultrasound}

34/43 patients categorized as GCA (79\%) had a positive compression sign and a positive halo sign, i. e., there was a $100 \%$ congruency between the compression and halo sign. None of the patients in the non-GCA group had a positive compression or halo sign. Based on these findings, the sensitivity and specificity and negative and positive predictive value of the compression and halo sign for the GCA and non-GCA groups were $79 \%$ and $100 \%$, and $80 \%$ and $100 \%$, respectively.

All 20 patients with active vasculitis on TA biopsy showed a positive compression and halo sign. In 10 patients with a positive compression and halo sign, the TA biopsy was negative. None of the patients lacking the compression and halo sign had active vasculitis on TA biopsy.

Stenosis or occlusion of the TA was detected infrequently (12\% and $7.5 \%$ among individuals in the GCA group, respectively, none in the non-GCA group, respectively). Of note, stenosis or occlusion was only observed in patients with a positive compression and halo sign. These CDU findings thus did not provide additional diagnostic information.

\section{Discussion}

$\nabla$

Vascular ultrasound as a noninvasive method able to monitor the TA (as well as many other arteries) in their entirety - hence overcoming the issue of inflammatory "skip lesions" - is widely accepted as a diagnostic tool of choice in patients with suspected GCA. Indeed, CDU has been shown to have a high sensitivity and
Table 1 Patient characteristics.

\begin{tabular}{|c|c|c|c|}
\hline & GCA $(n=43)$ & $\begin{array}{l}\text { Non-GCA } \\
(n=37)\end{array}$ & p-value \\
\hline female n (\%) & $25(58)$ & $30(70)$ & n. s. ${ }^{2}$ \\
\hline age years (mean $\pm S D$ ) & $75 \pm 8$ & $68 \pm 11$ & n. s. ${ }^{2}$ \\
\hline \multicolumn{4}{|l|}{ clinical presentation n (\%) } \\
\hline fever & $7(16)$ & $5(14)$ & n. s. ${ }^{3}$ \\
\hline vision disorder & $11(26)$ & $11(30)$ & n. s. ${ }^{3}$ \\
\hline headache & $26(60)$ & $15(42)$ & n. s. ${ }^{3}$ \\
\hline jaw claudication & $20(47)$ & $3(8)$ & $<0.001^{3}$ \\
\hline tenderness on scalp & $13(30)$ & $6(17)$ & n. s. ${ }^{3}$ \\
\hline prominent TA & $13(30)$ & $4(11)$ & $0.028^{3}$ \\
\hline polymyalgia & $16(37)$ & $17(47)$ & n. s. ${ }^{3}$ \\
\hline weight loss & $21(49)$ & $3(8)$ & $<0.001^{3}$ \\
\hline claudication & $1(2)$ & $2(5)$ & n. s. ${ }^{3}$ \\
\hline \multicolumn{4}{|l|}{ laboratory values } \\
\hline ESR mm/h & $76(61.95)$ & $42(11.60)$ & $0.003^{4}$ \\
\hline CRP mg/l & $65(36.114)$ & $13(6.47)$ & $0.004^{4}$ \\
\hline Lc $\times 10^{9} / \mathrm{I}($ mean $\pm S D)$ & $10.2 \pm 2.8$ & $9.3 \pm 3.4$ & n. s. ${ }^{3}$ \\
\hline $\mathrm{Hb} \mathrm{g/l} \mathrm{(mean \pm SD)}$ & $116 \pm 22$ & $118 \pm 26$ & n. s. ${ }^{3}$ \\
\hline $\mathrm{Tc} \times 10^{9} / \mathrm{l}($ mean $\pm \mathrm{SD})$ & $436 \pm 171$ & $347 \pm 171$ & n. s. ${ }^{4}$ \\
\hline biopsy performed n (\%) & $38^{5}(88)$ & $15(41)$ & $<0.001^{3}$ \\
\hline on steroids before CDU (days) & $1(0.3)$ & $2(0.5)$ & n. s. ${ }^{4}$ \\
\hline on steroids before biopsy (days) & $4(2.7)$ & $4(2.8)$ & n. s. ${ }^{4}$ \\
\hline days between CDU and biopsy & $3(1.5)$ & $2(1.5)$ & n. s. ${ }^{4}$ \\
\hline
\end{tabular}

${ }^{1} \mathrm{TA}=$ temporal artery, $\mathrm{ESR}=$ erythrocyte sedimentation rate, $\mathrm{CRP}=\mathrm{C}$-reactive protein, $\mathrm{Lc}=$ leucocytes, $\mathrm{Hb}=$ hemoglobin, $\mathrm{Tc}=$ thrombocytes, $\mathrm{CDU}=$ color duplex ultrasound.

${ }^{2}$ Student's t-test.

${ }^{3}$ Chi-square-test.

${ }^{4}$ Mann-Whitney-U-test.

${ }^{5}$ One biopsy revealed only a venous segment. ESR and CRP, on steroids before CDU and biopsy, respectively, as well as days between CDU and biopsy are given as median ( $25-75$ percentile).

excellent specificity in patients with suspected GCA assessed in experienced centers $[1,4]$. However, other studies (including meta-analyses) indicated that the diagnostic performance of currently established CDU criteria is highly operator-dependent and is thus susceptible to producing misleading artifacts if not applied by trained experts using appropriate equipment $[5,8,9]$. Indeed, as exemplified in 0 Fig. 2, a thickened vessel wall (halo sign) can easily be missed or wrongfully diagnosed if the respective color gain is chosen inappropriately high or low.

Against this background, we tested a new and simple diagnostic ultrasound criterion - termed 'compression sign' - relying on the B-mode modality only and thus avoiding the above-mentioned drawbacks of CDU. The diagnostic performance of the compression sign was assessed on the basis of the groups GCA and nonGCA established based also on ACR criteria by a team of independent, experienced physicians. Notably, the diagnostic performance of the compression sign and the halo sign was identical, and in all cases in which the TA biopsy was positive, the compression sign and the halo sign were positive as well. The fact that the compression sign was negative in 9/43 study participants in the GCA group is consistent with the fact that extensive inflammation of the TA is not always present in GCA patients $[10,11]$. Extended vascular ultrasound examination - as previously reported by our group - or additional imaging modalities may thus have to be considered as part of the diagnostic work-up in individuals with suspected GCA $[1,12,13]$.

There are several limitations in this study. First, the number of patients included is relatively small. Second, although the examiner 


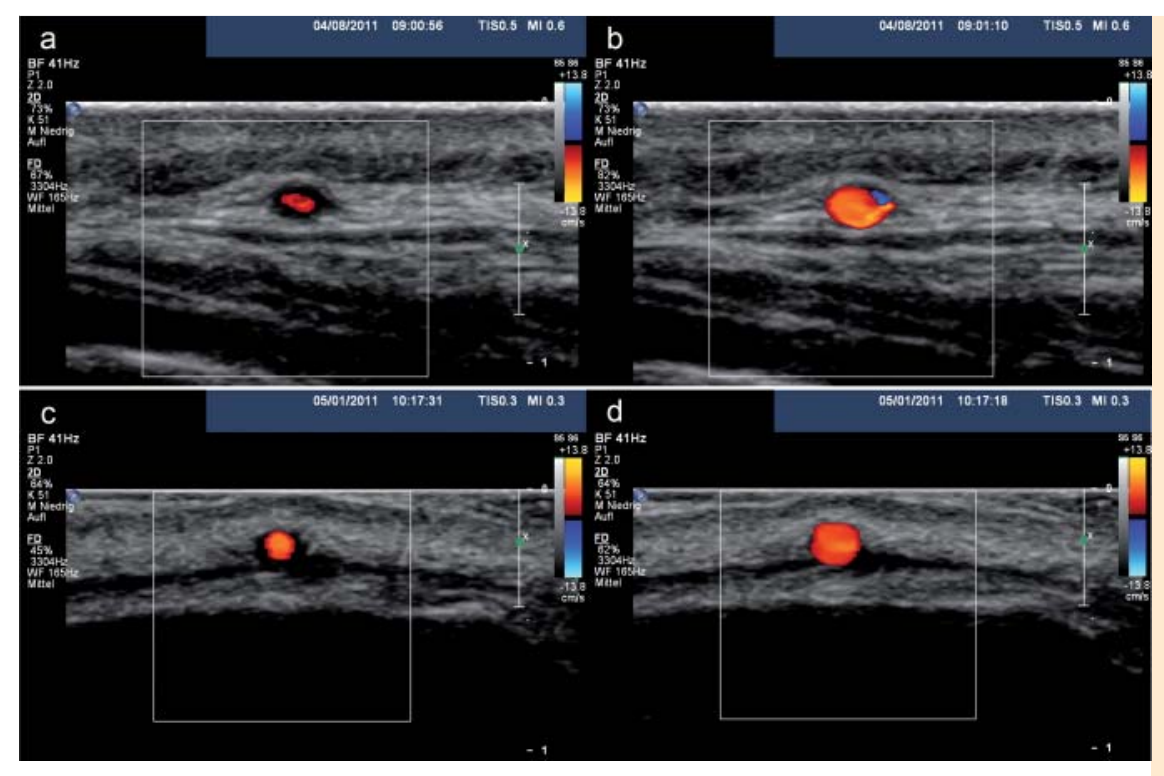

Fig. 2 Inadequate color-gain may impact interpretation when searching for a halo.Identical setting on CDU scanner in all panels, except for color-gain. a and $\mathbf{b}$ Healthy individual: color-gain too low - mimicking a halo sign a. Appropriate color-gain (b). c and $\mathbf{d}$ Individual with biopsy-proven temporal arteritis: appropriate color-gain demonstrating a halo (c).

Over-steered color-gain covering the thickened arterial wall (d).

Abb. 2 Nicht korrekter Color-Gain beeinflusst Interpretation des „Halo-Zeichens“. Identisches Apparate-Setting auf allen Bildern mit Ausnahme des Color-Gain. a und $\mathbf{b}$ Gesundes Individuum: ColorGain zu tief - imitiert ein „Halo-Zeichen“ a. Korrekter Color-Gain (b).

c und $\mathbf{d}$ Patient mit bioptisch nachgewiesener Temporalarteritis: Color-Gain korrekt mit Nachweis eines "Halo-Zeichens" (c).

Color-Gain übersteuert - Überdeckung der verdickten Gefäßwand (d).

was unaware of the diagnosis at the time of CDU, the compression sign was not tested independently from the halo sign and thus such a bias cannot be completely excluded. Third, the study design also does not allow for interobserver comparison for the two signs individually.

In conclusion, in this cohort of individuals with suspected GCA, the halo sign and the compression sign were equal with respect to their diagnostic performance. The simplicity of the compression sign suggests a clinical potential warranting further evaluation. Clearly, further prospective studies are needed to investigate this new ultrasound finding in different patient cohorts and study centers.

* Equal contributors.

\section{Funding}

Swiss National Science Foundation Grant (SNSF 31 003A_135677) to $\mathrm{CH}$.

\section{Acknowledgments \\ $\nabla$}

We thank all contributors to the 'BARK' cohort study.

\section{References}

1 Aschwanden M, Kesten F, Stern $M$ et al. Vascular involvement in patients with giant cell arteritis determined by duplex sonography of 2×11 arterial regions. Ann Rheum Dis 2010; 69: 1356-1359

2 Tato F, Hoffmann $U$. Giant cell arteritis: a systemic vascular disease. Vasc Med 2008; 13: 127-140

3 Breuer GS, Nesher G, Nesher R. Rate of discordant findings in bilateral temporal artery biopsy to diagnose giant cell arteritis. J Rheumatol 2009; 36: $794-796$

4 Schmidt WA, Kraft HE, Vorpahl K et al. Color duplex ultrasonography in the diagnosis of temporal arteritis. N Engl J Med 1997; 37: 1336-1342

5 Schmidt WA, Blockmans D. Use of ultrasonography and positron emission tomography in the diagnosis and assessment of large-vessel vasculitis. Curr Opin Rheumatol 2005; 17: 9-15

6 Salvarani C, Silingardi M, Ghirarduzzi A et al. Is duplex ultrasonography useful for the diagnosis of giant-cell arteritis? Ann Intern Med 2002 137: $232-238$

7 Hunder GG, Bloch DA, Michel BA et al. The American College of Rheumatology 1990 criteria for the classification of giant cell arteritis. Arthritis Rheum 1990; 33: 1122 - 1128

8 Arida A, Kyprianou M, Kanakis $M$ et al. The diagnostic value of ultrasonography-derived edema of the temporal artery wall in giant cell arteritis: a second meta-analysis. BMC Musculoskelet Disord 2010; 11: 44

9 Ball EL, Walsh SR, Tang TY et al. Role of ultrasonography in the diagnosis of temporal arteritis. Br J Surg 2010; 97: 1765-1771

10 Schmidt WA, Seifert A, Gromnica-Ihle $E$ et al. Ultrasound of proximal upper extremity arteries to increase the diagnostic yield in large-vessel giant cell arteritis. Rheumatology 2008; 47: 96-101

11 Brack A, Martinez-Taboada V, Stanson A et al. Disease pattern in cranial and large-vessel giant cell arteritis. Arthritis Rheum 1999; 42: 311-317

12 Janssen SP, Comans EH, Voskuyl AE et al. Giant cell arteritis: heterogeneity in clinical presentation and imaging results. J Vasc Surg 2008; 48: $1025-1031$

13 Blockmans D. PET in vasculitis. Ann N Y Acad Sci 2011; 1228: 64-70 